\title{
Nurses' Perspectives on the Impact of Marketing Mix Elements (7Ps) on Patients' Tendency to Kind of Hospital
}

\author{
Ghasem Abedi ${ }^{1}$, Roya Malekzadeh ${ }^{2}$, Mahmood Moosazadeh ${ }^{1}$, Ehsan Abedini ${ }^{3}$, \\ Edris Hasanpoor ${ }^{4,5^{*}}$
}

\footnotetext{
OPEN ACCESS

Citation: Ghasem Abedi, Roya Malekzadeh, Mahmood Moosazadeh, Ehsan Abedini, Edris Hasanpoor. Nurses' Perspectives on the Impact of Marketing Mix Elements (7Ps) on Patients' Tendency to Kind of Hospital. Ethiop J Health Sci. 2018;29(2):223.

doi:http:// dx.doi.org/10.4314ejhs.v29i2.9

Received: September 20, 2018

Accepted: October 26, 2018

Published: March 1, 2019

Copyright: (C) 2019 Abedi G., et al. This is an open access article distributed under the terms of the Creative Commons Attribution License, which permits unrestricted use, distribution, and reproduction in any medium, provided the original author and source are credited. Funding: Nil.

Competing Interests: The authors declare that this manuscript was approved by all authors in its form and that no competing interest exists.

Affiliation and Correspondence:

${ }^{1}$ Health Sciences Research Center,

Mazandaran University of Medical Sciences, Sari, Iran

${ }^{2}$ Educational Vice Chancellor, Mazandaran University of Medical Sciences, Sari, Iran

${ }^{3}$ Student Research Committee, Health Sciences Research Center, Mazandaran University of Medical Sciences, Sari, Iran

${ }^{4}$ Research Center for EvidenceBased Health Management, Maragheh University of Medical Sciences, Maragheh, Iran

${ }^{5}$ Clinical Research Development Unit, Shahid Beheshti Hospital, Maragheh University of Medical Sciences, Maragheh, Iran

*Email: edihasanpoor@gmail.com
}

\begin{abstract}
BACKGROUND: Marketing mix (7PS) is a critical concept in healthcare management and health marketing. Hence, this study was conducted to investigating the role of $7 P$ s on patients' disposition to the kind of hospital from nurses' perspectives. METHODS: A cross-sectional study design was used in 2015. The study was conducted in one state in Iran (Mazandaran). The statistical population included nurses $(n=235)$ in public and private hospitals were selected randomly through the list. Data were collected by questionnaire and were analyzed using SPSS software (version 22).

RESULTS: The results showed that 38.6 percent of nurses were males and the others (61.4 percent) were females. Their mean age was 31.0 7.1 years, and the majority of them belonged to the 30-40 age group. The mean work experience of them was $11.42 \pm 6.5$ years. The findings showed that there were significant differences between nurses' perspectives in public and private hospitals about the effect of 7Ps elements on patients' tendency to the public and private hospitals $(p<0.05)$.

CONCLUSIONS: According to the results, the officials of public hospitals should take more attention to the elements like product, place, promotion, people, physical assets and process management more than the past because these elements cause that the patients are disposed to the private hospitals while the government make more investment in public hospitals.
\end{abstract}

KEYWORDS: Marketing mix, 7Ps, hospital, nursing

\section{INTRODUCTION}

Nowadays, increasing people's awareness of healthcare and therapeutic affairs on one the hand and multiplicity of healthcare services providers on the other hand, made the attracting, retaining and satisfying of patients harder than ever, because they can choose the healthcare services with more diversity (1). Hence, in a competition, those organizations will be succeed that attempt to create superior value for patients (customers) through a strategic marketing tool as titled with "marketing mix elements (7Ps)" (2). 7Ps can be classified into seven major strategies like as product/service, price, place, promotion, people, physical assets and process (3). This 
is a known marketing strategy that has provided a critical tool for hospitals and medical services centers to improve the management of healthcare marketing (4). Services marketing mix elements and their parameters, that can affect the tendency of patients to kind of hospital, are introduced in Table 1 (2). 7Ps that may attract the patients' (customers') to the hospitals and other healthcare services centers can led to: 1) patient satisfaction, 2) services utility, 3) public awareness, 4) better care of vulnerable people, 5) take attention to the ethical issues of patients, 6) improvement of services cost-effectiveness (5). Leiderman et al. revealed that the hospitals are divided into two main groups: a) good infrastructure and equipment, with a well-defined investment policy in marketing; b) worse infrastructure and less equipment, with lower proportional investment in marketing (6). Patients' satisfaction derived from 7Ps can led to the fast rehabilitation of patients (5). Patients' engagement has been critically considered as an index to show the quality of care provided by the healthcare system (7).

Table 1: Services marketing mix and their parameters $(1,3,10)$

\begin{tabular}{|c|c|c|}
\hline Elements & Definition & Parameters \\
\hline Product & $\begin{array}{l}\text { Therapeutic and medical } \\
\text { services provided in } \\
\text { hospital }\end{array}$ & $\begin{array}{l}\text { Providing the new services with new method, type of expertise, quality } \\
\text { of provided services in the field of accuracy, comprehensiveness of } \\
\text { services (provide all therapeutic and medical services), therapeutic } \\
\text { consultation services, quality of provided services in the field of speed, } \\
\text { quality of provided services in the field of precision, professional health } \\
\text { care, suitable outpatient services, Para clinical services, surgery services, } \\
\text { suitable inpatient services }\end{array}$ \\
\hline Price & $\begin{array}{l}\text { Final cost of Therapeutic } \\
\text { and medical services } \\
\text { provided }\end{array}$ & $\begin{array}{l}\text { Appropriate discount from the hospital, split payment of therapeutic } \\
\text { cost, lower cost in public hospital, suitable payment contribution for } \\
\text { patient, insurance type, facilities for payment }\end{array}$ \\
\hline Place & $\begin{array}{l}\text { Internal and external } \\
\text { environment of hospital }\end{array}$ & $\begin{array}{l}\text { Proximity to home, appearance of hospital, suitable heating and cooling } \\
\text { system, green space of hospital, parking for visitors, internal decoration } \\
\text { and beauty of sections }\end{array}$ \\
\hline Promotion & $\begin{array}{l}\text { Promotion from hospital } \\
\text { to attract the patient`s } \\
\text { tendency }\end{array}$ & $\begin{array}{l}\text { Consulting with staff and personnel of hospital, providing therapeutic } \\
\text { consultation, publication of magazines, attractive and sufficient } \\
\text { promotion in multimedia, reputation of hospital, physician's idea, } \\
\text { previous experience and awareness, consulting with informants, friends } \\
\text { and relatives idea, antiquity of hospital }\end{array}$ \\
\hline People & $\begin{array}{l}\text { Staff and personnel of } \\
\text { hospital providing } \\
\text { Therapeutic and medical } \\
\text { services }\end{array}$ & $\begin{array}{l}\text { Trained and ethical personnel, continuous presence of physicians and } \\
\text { nurses around the patient, technical personnel, personnel`s skill in their } \\
\text { job, personnel's speed and precision, personnel's suitable appearance, } \\
\text { personnel's courteous, respectful and good behavior }\end{array}$ \\
\hline $\begin{array}{l}\text { Physical } \\
\text { assets }\end{array}$ & $\begin{array}{l}\text { All of facilities and } \\
\text { equipment belong } \\
\text { hospital }\end{array}$ & $\begin{array}{l}\text { modern therapeutic equipment, fulfillment of different Para clinical } \\
\text { services, facilities of receiving and paying the cash, internet reservation } \\
\text { for care, good hoteling services, transportation services for patient }\end{array}$ \\
\hline $\begin{array}{c}\text { Process } \\
\text { management }\end{array}$ & $\begin{array}{l}\text { Work trend management } \\
\text { in hospital }\end{array}$ & $\begin{array}{l}\text { Speed of personnel's doing job, personnel's continuous presence even } \\
\text { during the time shift, simplify the services providing, observance the } \\
\text { bureaucratic discipline, precision in service providing, Getting } \\
\text { admission in less time }\end{array}$ \\
\hline
\end{tabular}

Given their first-hand experience of every stage of the care pathway, patients are legitimately positioned to evaluate the care and services received, or whether their needs and preferences were met or not $(8,9)$. Nurses as the biggest group of health care providers in the hospitals have an important role in rendering cares (10). In hospitals and clinics, nurses often are in contact with patients and their family, so they have an active role on improvement of patients'

DOI: http://dx.doi.org/10.4314/ejhs.v29i2.9 
conditions on one hand $(11,12)$ and can comment about their side issues like referral to the hospital in other hand. Therefore, clear understanding, anticipating, evaluating, and directing the health and therapeutic needs of patients from nurses, particularly, are the principles of any activity in healthcare organizations (2). Thus, investigation of nurses' perspectives provides valuable feedback for officials and authorities to consider the 7Ps as a proper tool to make and deliver better healthcare services. Therefore, this study was designed and conducted to investigate the effect of 7Ps on patients' tendency to the public and private hospitals from nurses' perspectives and finally, to determine what elements cause patients' disposition to the public and what elements to private hospitals.

\section{METHODS}

A cross-sectional study design was used in the city of Sari, Iran, 2015. The statistical population composed of nurses who were working in two public and two private hospitals in Sari City (center of Mazandaran province in Northern Iran). The statistical sample volume 236 (composed of 158 public +78 private) was calculated through Cochran's formula and segmented to public and private hospitals according to quota sampling. Data collected by Abedi's questionnaire (5) consisted of two parts. The first part included personal information (gender, age, experience) and the second part included 54 questions regarding 7Ps factors composed of product (12 items), price (6 items), place (6 items), promotion (10 items), people (7 items), physical assets (6 items) and process management (6 items). Each question was answered according to Likert scale (very low, low, middle, high and very high) pointed with 1 to 5, respectively. The validity of the questionnaire was confirmed through structural validity. The reliability was 0.85 in this study that closed to 0.86 claimed in Abedi's study (5). Data were analyzed using descriptive and inferential statistics including independent-sample $t$ test by SPSS 22.

Ethical aspects: The study was approved by the Ethical Committee of Mazandaran University of Medical Sciences (Ethical code of project: 91-114). The participants were informed in relation with the objective and the method of the study, and they were accepted to consent in order to participate in the study.

\section{RESULTS}

The results showed that 38.6 percent of the nurses were males and the other (61.4 percent) were females. The mean age of nurses was $31.0 \pm 7.1$ years; the majority of them belonged to the 30-40 age group. Their mean work experience was $11.42 \pm 6.5$ years. The descriptive statistics of 7Ps elements is shown in Table 2.

Table 2: Mean and Std. Deviation of 7Ps elements

\begin{tabular}{cccccc}
\hline 7Ps elements & Hospital & $\mathrm{N}$ & Mean & Std. Deviation & Std. Error Mean \\
Product/service & public & 158 & 2.89 & 0.45 & 0.03 \\
& private & 78 & 3.71 & 0.69 & 0.07 \\
price & public & 158 & 3.66 & 1.01 & 0.08 \\
& private & 78 & 2.59 & 0.97 & 0.11 \\
place & public & 158 & 2.52 & 0.65 & 0.05 \\
& private & 78 & 3.04 & 0.96 & 0.10 \\
promotion & public & 158 & 2.02 & 0.40 & 0.03 \\
People/staff & private & 78 & 3.37 & 0.79 & 0.09 \\
& public & 158 & 2.87 & 0.60 & 0.04 \\
Physical assets & private & 78 & 3.93 & 0.83 & 0.09 \\
Process management & public & 158 & 2.02 & 0.42 & 0.03 \\
& private & 78 & 3.05 & 0.91 & 0.10 \\
& public & 158 & 2.79 & 0.44 & 0.03 \\
\end{tabular}

As shown in Table 2, mean price element $(3.71 \pm$ 0.69 ) in public hospitals is more toward private

DOI: http://dx.doi.org/10.4314/ejhs.v29i2.9 
hospitals, from nurses' perspectives. In other elements, nurses in private hospitals have given more points rather than nurses in public hospitals.

The results showed that there is a significant difference between nurses' perspectives about all
7Ps elements in patients' tendency to the public and private hospitals $(\mathrm{p}<0.05)$. According to the mean difference column, only the price mean difference between public and private hospitals was positive $\left(\mu_{\text {public }}-\mu_{\text {private }}>0\right)($ Table 3$)$.

Table: Overview of 7Ps elements

\begin{tabular}{|c|c|c|c|c|c|c|c|c|c|}
\hline \multicolumn{2}{|c|}{ 7Ps elements } & \multicolumn{2}{|c|}{$\begin{array}{l}\text { Leven's test } \\
\text { for equality of } \\
\text { variances }\end{array}$} & \multicolumn{6}{|c|}{ t-test } \\
\hline & & \multirow[t]{2}{*}{$\mathrm{F}$} & \multirow[t]{2}{*}{ Sig. } & \multirow[t]{2}{*}{ Df } & \multirow{2}{*}{$\begin{array}{c}\text { Sig. } \\
\text { (2-tailed) }\end{array}$} & \multirow{2}{*}{$\begin{array}{c}\text { Mean } \\
\text { difference }\end{array}$} & \multirow{2}{*}{$\begin{array}{l}\text { Std.error } \\
\text { difference }\end{array}$} & \multicolumn{2}{|c|}{$95 \%$ Confidence Interval } \\
\hline & & & & & & & & Lower & Upper \\
\hline \multirow[t]{2}{*}{ Product } & $*$ & 18.650 & 0.000 & 234 & 0.000 & -0.82448 & 0.07553 & -0.97327 & -0.67568 \\
\hline & $* *$ & & & 109.847 & 0.000 & -0.82448 & 0.08691 & -0.99671 & -0.65224 \\
\hline \multirow[t]{2}{*}{ Price } & $*$ & 0.002 & 0.966 & 234 & 0.000 & 1.07368 & 0.13820 & 0.80140 & 1.34595 \\
\hline & $* *$ & & & 158.964 & 0.000 & 1.07368 & 0.13637 & 0.80435 & 1.34300 \\
\hline \multirow[t]{2}{*}{ Place } & $*$ & 13.552 & 0.000 & 234 & 0.000 & -0.52488 & 0.10684 & -0.73538 & -0.31438 \\
\hline & $* *$ & & & 113.523 & 0.000 & -0.52488 & 0.12105 & -0.76470 & -0.28507 \\
\hline \multirow[t]{2}{*}{ Promotion } & $*$ & 32.884 & 0.000 & 234 & 0.000 & -1.35417 & 0.07798 & -1.50780 & -1.20054 \\
\hline & $* *$ & & & 96.758 & 0.000 & -1.35417 & 0.09578 & -1.54428 & -1.16406 \\
\hline \multirow[t]{2}{*}{ People } & $*$ & 11.811 & 0.001 & 234 & 0.000 & -1.06331 & 0.09504 & -1.25056 & -0.87606 \\
\hline & $* *$ & & & 117.926 & 0.000 & -1.06331 & 0.10583 & -1.27288 & -0.85374 \\
\hline \multirow{2}{*}{$\begin{array}{l}\text { Physical } \\
\text { assets }\end{array}$} & $*$ & 62.754 & 0.000 & 234 & 0.000 & -1.02810 & 0.08720 & -1.19991 & -0.85630 \\
\hline & $* *$ & & & 93.571 & 0.000 & -1.02810 & 0.10916 & -1.24486 & -0.81134 \\
\hline \multirow{2}{*}{$\begin{array}{c}\text { Process } \\
\text { management }\end{array}$} & $*$ & 47.613 & 0.000 & 234 & 0.000 & -0.95037 & 0.08480 & -1.11743 & -0.78330 \\
\hline & $* *$ & & & 98.537 & 0.000 & -0.95037 & 0.10313 & -1.15500 & -0.74573 \\
\hline \multicolumn{10}{|c|}{ * Equal variance $* *$ Not equal variances } \\
\hline
\end{tabular}

The main reasons of differences between patients' perspectives in private and public hospitals are shown in Table 4. As shown in Table 4, the most important reason of difference between nurses' perspectives in public and private hospitals about product is "surgery services", $4.06 \pm 0.87$ in private and $2.85 \pm 0.73$ in public hospitals. In addition, the highest mean score of the 7Ps were found in relation to "low cost"; it was $1.94 \pm 1.58$ and $4.10 \pm 1.02$ in private and public hospitals, respectively. Moreover, the mean "green space of hospital" as one of the reason in differences between nurses' perspective was $3.15 \pm 1.27$ in private and $1.94 \pm 0.62$ in public hospitals. Reason of "physicians' idea" was $4.19 \pm 0.99$ in private hospitals. This was $2.49 \pm 1.00$ in public hospitals. People as one of the elements of 7Ps for reason of "personnel's courteous, respectful and good behavior" were $4.18 \pm 0.97$ in private and $2.83 \pm 0.65$ in public hospitals.

Also, about physical assets, the factor of "facilities of receiving and paying the cash" was $3.26 \pm 1.07$ and $1.84 \pm 0.69$ in private and public hospitals, respectively. Finally, about process management factor of "personnel's continuous presence even during the time shift" was $3.87 \pm$

DOI: http://dx.doi.org/10.4314/ejhs.v29i2.9 
0.98 in private hospital and $2.85 \pm 0.51$ in public hospitals.

Table 4: Main reasons of differences between nurses' perspectives in public and private hospitals

\begin{tabular}{|c|c|c|c|}
\hline \multirow[t]{2}{*}{ 7Ps elements } & \multirow[t]{2}{*}{ Reason } & Public & private \\
\hline & & Mean \pm SD & Mean \pm SD \\
\hline \multirow[t]{4}{*}{ product } & Accuracy of delivered healthcare services & $2.91 \pm 0.62$ & $3.81 \pm 0.80$ \\
\hline & surgery services & $2.85 \pm 0.73$ & $4.06 \pm 0.87$ \\
\hline & Para clinical services & $2.81 \pm 0.60$ & $3.95 \pm 0.88$ \\
\hline & Suitable outpatient services & $2.71 \pm 0.77$ & $3.86 \pm 0.83$ \\
\hline \multirow[t]{4}{*}{ price } & suitable payment contribution for patient & $3.63 \pm 1.03$ & $2.41 \pm 1.32$ \\
\hline & Appropriate discount from the hospital & $3.46 \pm 1.16$ & $2.26 \pm 1.24$ \\
\hline & facilities for payment & $3.29 \pm 1.27$ & $2.12 \pm 1.29$ \\
\hline & low cost & $4.10 \pm 1.02$ & $1.94 \pm 1.58$ \\
\hline \multirow[t]{3}{*}{ place } & appearance of hospital & $2.27 \pm 0.94$ & $3.14 \pm 1.21$ \\
\hline & internal decoration and beauty of sections & $2.28 \pm 0.77$ & $3.05 \pm 1.15$ \\
\hline & Green space of hospital & $1.94 \pm 0.62$ & $3.15 \pm 1.27$ \\
\hline \multirow[t]{5}{*}{ promotion } & attractive and sufficient promotion in multimedia & $1.25 \pm 0.52$ & $2.76 \pm 1.16$ \\
\hline & reputation of hospital & $2.24 \pm 1.04$ & $3.85 \pm 1.03$ \\
\hline & antiquity of hospital & $2.22 \pm 0.82$ & $3.68 \pm 1.01$ \\
\hline & friends and relatives for their idea & $2.01 \pm 0.88$ & $3.68 \pm 1.09$ \\
\hline & physician's idea & $2.49 \pm 1.00$ & $4.19 \pm 0.99$ \\
\hline \multirow[t]{4}{*}{ people } & Trained and ethical personnel & $2.80 \pm 0.81$ & $4.03 \pm 1.01$ \\
\hline & technical personnel & $2.91 \pm 0.52$ & $3.94 \pm 0.94$ \\
\hline & personnel's suitable appearance & $2.89 \pm 0.80$ & $3.90 \pm 1.05$ \\
\hline & personnel's courteous, respectful and good behavior & $2.83 \pm 0.65$ & $4.18 \pm 0.97$ \\
\hline \multirow[t]{4}{*}{ Physical assets } & facilities of receiving and paying the cash & $1.84 \pm 0.69$ & $3.26 \pm 1.07$ \\
\hline & Modern therapeutic equipment & $2.51 \pm 0.72$ & $3.79 \pm 0.98$ \\
\hline & Internet reservation for care & $1.29 \pm 0.53$ & $2.46 \pm 1.39$ \\
\hline & transportation services for patient & $1.28 \pm 0.45$ & $2.38 \pm 1.39$ \\
\hline \multirow{3}{*}{$\begin{array}{c}\text { Process } \\
\text { management }\end{array}$} & Speed of personnel's doing job & $2.80 \pm 0.70$ & $3.82 \pm 1.04$ \\
\hline & personnel's continuous presence during the time shift & $2.85 \pm 0.51$ & $3.87 \pm 0.98$ \\
\hline & observance of the bureaucratic discipline & $2.85 \pm 0.57$ & $\begin{array}{c}3.83 \pm \\
1.02\end{array}$ \\
\hline
\end{tabular}

\section{DISCUSSION}

This study addressed the effect of 7Ps on patients' tendency to public and private hospitals from

DOI: http://dx.doi.org/10.4314/ejhs.v29i2.9 
nurses' perspective. The results showed that in the public hospitals, nurses' perspective about all 7Ps elements significantly differs from each other. The investigations revealed that the main reason of differences between nurses' perspective in public and private hospitals about product is "surgery services"; in private hospitals it was more than in public hospitals. This means that better surgery services are provided for patients in private hospitals.

The highest mean scores of the 7Ps was found in relation to "low cost"; it was $1.94 \pm 1.58$ and $4.10 \pm 1.02$ in private and public hospitals, respectively. It means that the most patients refer to the public hospitals due to low cost of care services. About place is "green space of hospital", in private more than in public hospitals. The highest mean scores promotion were found in relation to "physicians' idea" in private hospitals that it is more than the public hospitals. The highest mean scores people were found in relation to "personnel's courteous, respectfulness and good behavior" in public hospitals that it is more than the private hospitals. In addition, the highest mean scores physical assets were found in relation to "facilities of receiving and paying the cash" in private hospitals that it is more than the public hospitals. The highest mean scores process management were found in relation to "personnel's continuous presence even during the time shift" in private hospitals that it is more than the public hospitals.

Behboodi did a research entitled "Effective Factors in the Choosing Public or Private Hospitals by patients who required surgery. According to Behboodi's study, economic factors were the most effective in choosing the hospitals which in consistent of the results of this study (13). Sepehri et al. investigated the impact of health insurance on the hospital admission length of stay in Vietnam and showed that insurance type had different effects on the selection of hospitals and the mean of stay length (14). In a study by Khayatan et al. as investigation of affecting factors on the access to services from the perspective of workers in urban health centers in the city of Rey, financial ability was identified as an important factor for accessibility to health care. On the other hand, comparison of patients' and nurses' viewpoints in private hospitals showed that these two groups had similar perspectives about the effect of product, price, place and process management in patients tendency to private hospitals. However, they had different viewpoints about people and physical assets (15).

A research conducted by Whitehead et al. entitled "Effective Factors on the Understanding of Patients from the Sanitary of NHS Hospitals or Their Trust" depicted that the location features are the most important factors in choosing a hospital (16). Ghazanfari and Tirgari in a survey entitled "Effective Factors on Selection of Governmental or Private Hospitals in Patients Requiring Surgery in Kerman showed that the majority of patients had been admitted in governmental hospitals. The priority of effective factors on selection of governmental hospitals was the quality of nursing services, and this priority in private hospitals was the possibility of free visit time. They also found that by improving the financial situation and possibility of free visit time, patients who were admitted in private hospitals also prefer governmental hospitals for surgery (17).

Jalili et al. showed that there is a direct interdependence between selecting a hospital (public or private) and the three factors of social elements, hospital services and hospital facilities. Based on logistic regression analysis, the patients' priorities for hospital choosing were hospital services, social elements and hospital facilities (18). Jannati et al. showed that some factors including referring to hospital by ambulance, physicians' advice, family income, insurance type, hospital services quality, employment of patients' family members in hospital, cost of services provided at hospital and information given to patients about their diseases are the factors that affect the hospital selection decision by patients (19).

According to the results from our study, the officials of public hospitals should take attention to the components like product, place, promotion,

DOI: http://dx.doi.org/10.4314/ejhs.v29i2.9 
people, physical assets and process management more than the past because these components cause that the patients dispose to the private hospitals while the government make more investment in public hospitals. In addition, it can be concluded that nurses' perspectives about the elements of marketing mix provide an opportunity to better understand them and their parameters in public and private hospitals. Also, the place of each factor associated with patients' tendency to the hospitals makes it easy to review the strengths and weaknesses of hospital administration.

\section{ACKNOWLEDGEMENTS}

The authors would like to thank all professional nurses who participated in this study.

\section{REFERENCES}

1. Tabrizi JS, HaghGoshayie E, Doshmangir L, Yousefi M. New public management in Iran's health complex: a management framework for primary health care system. Primary health care research \& development. 2018 May;19(3):264-76.

2. Abedi G, Abedini E. Prioritizing of marketing mix elements effects on patients' tendency to the hospital using analytic hierarchy process. International Journal of Healthcare Management. 2017;10(1):34-41.

3. Sreenivas SB, Srinivasarao U. An analysis on marketing mix in hospitals. International Journal of Advanced Research in Management and Social Sciences. 2013;2(4):21.

4. Nasiripour A, AkbarianBafghi M, Maleki M, Raeissi P. A mixed model for health services marketing in Iranian public hospitals. Journal of Health Information Management. 2011;9(7):1158-68.

5. Abedi RZ, Abedini E, Rostami F. Surveying the impact of services marketing mix components (7Ps) on patients' disposition towards the public \& private hospitals of Sari City. jhosp. 2013;13(4):9.

6. Leiderman EB, Zucchi P. Hospital marketing: characterization of marketing actions in private hospitals in the city of Sao Paolo-
Brazil. World Hosp Health Serv. 2010;46(4):28.

7. Hasanpoor E, Janati A, Arab-Zozani M, Haghgoshayie E. Using the evidence-based medicine and evidence-based management to minimise overuse and maximise quality in healthcare: a hybrid perspective. BMJ Evidence-Based Medicine. 2018; 24(6).

8. Hasanpoor E, Bahadori M, Yaghoubi M, Haghgoshayie E, Mahboub-Ahari A. Evidence-based management as a basis for evidence-based medical consultation. BMJ evidence-based medicine. 2018 Nov 29:bmjebm-2018.

9. Tabrizi JS, Goshayie EH, Doshmangir L, Yousefi M. The Barriers to Implementation of New Public Management Strategies in Iran's Primary Health Care: A Qualitative Study. Journal of the liaquat university of medical and health sciences. 2018; 17(1):817.

10. Sandvoll GE, Kristoffersen K, Hauge S. When care situations evoke difficult emotions in nursing staff members: an ethnographic study in two Norwegian nursing homes. $B M C$ Nurs. 2015;14(40):6-20.

11. Bryant-Lukosius D. A frame work for the introduction and evaluation of advanced practition nursing roles. Journal of advanced nursing 2008;48(5):11-15.

12. Williams D. An analysis of the nurse practitioner role in palliative care. CJN. 2001;14(4):7-18.

13. Behboudi F. Effective factors on the public or private hospital selection by patients that need surgical operation. Journal of Gilan Medical Sciences University. 2000;9(3536):7-22.

14. Sepehri SW, Sarma S. The influence of health insurance on hospital admission and length of stay--the case of Vietnam. Soc Sci Med. 2006;63(7):14-26.

15. Khayatan NA, Amini M, Mohammadnegad M. Effective factors on the people achievement to the presented services from health care staff Journal of Paramedics Faculty of Tehran Medical Sciences University. 2010;4(3):10-28.

DOI: http://dx.doi.org/10.4314/ejhs.v29i2.9 
16. Whitehead H, May, D., Agahi, H. An exploratory study into the factors that influence patients' perceptions of cleanliness in an acute NHS trust hospital. Journal of facilities management 2007;5(4):15.

17. Ghazanfari TB. Effective Factors on Selection of Governmental or Private Hospitals in Patients Requiring Surgery in Kerman. Health Strides in Nursing and Midwifery. 2014;1(1):7.
18. Jalili AM, Mahdavi AS. Studying the Factors for Selecting Public or Private Hospitals by Non Emergent Patients of Ardabil District in 2012. J Ardabil Univ Med Sci. 2014;14(4):10-19.

19. Jannati BM, Gholizadeh M, Alizadeh L, Khodayari MT. A Survey of Factors Affecting Patients' Decision in Selecting Governmental and Private Hospitals in Tabriz, Iran. $J$ Tourism Res Hospitality. 2013;2:(1): 15-26.

DOI: http://dx.doi.org/10.4314/ejhs.v29i2.9 